\title{
Convergent Motor Patterns from Divergent Circuits
}

\author{
Shari R. Saideman, Dawn M. Blitz, and Michael P. Nusbaum \\ Department of Neuroscience, University of Pennsylvania School of Medicine, Philadelphia, Pennsylvania 19104-6074
}

\begin{abstract}
Neuromodulation changes the cellular and synaptic properties of neurons, thereby enabling individual neuronal circuits to generate multiple activity patterns. However, distinct modulatory inputs could conceivably also configure different motor circuits to generate similar activity patterns. Using the isolated stomatogastric ganglion (STG) of the crab Cancer borealis, we showed previously that pyrokinin (PK) peptides activate the gastric mill (chewing) rhythm without the participation of the projection neuron modulatory commissural neuron 1 (MCN1). MCN1, which does not contain the PK peptide, also activates the gastric mill rhythm and, at these times, is a gastric mill central pattern generator $(\mathrm{CPG})$ neuron. Here, we show that the gastric mill rhythms elicited by PK superfusion and MCN1 stimulation in the isolated STG are comparable, in contrast to the distinct gastric mill rhythms elicited by other input pathways. We also identified several cellular and synaptic mechanisms underlying the PK- and MCN1-elicited gastric mill rhythms that are distinct, including additional differences in their core CPG neurons. For example, the presence of the inhibitory synapse from the pyloric pacemaker neuron anterior burster onto the gastric mill CPG was necessary only for generation of the PK-elicited gastric mill rhythm. Similarly, the dorsal gastric motor neuron regulated only the PK rhythm, apparently because of PK-mediated enhancement of its synaptic actions. Thus, we demonstrate that different modulatory inputs can elicit comparable, as well as distinct activity patterns from the same neuronal ensemble. Moreover, these comparable rhythms can result from distinct CPGs using overlapping, but distinct sets of cellular and synaptic mechanisms.
\end{abstract}

Key words: stomatogastric; gastric mill rhythm; neuromodulation; pyrokinin peptides; projection neuron; central pattern generator

\section{Introduction}

Neuromodulation changes the cellular and synaptic properties of neurons, enabling individual motor circuits to generate different motor patterns underlying distinct behaviors (Stein et al., 1997; Marder and Bucher, 2001; Marder et al., 2005; Grillner, 2006). These neuromodulators gain access to their neuronal circuit targets via local neuronal release and as circulating hormones. Less well established is whether different modulatory inputs can elicit comparable motor patterns and, if so, to what extent they share the same core central pattern generator $(\mathrm{CPG})$.

We addressed this issue using the stomatogastric nervous system (STNS) of the crab Cancer borealis (Nusbaum and Beenhakker, 2002; Marder and Bucher, 2007). Within the four ganglia of the STNS are a set of interacting CPG circuits that underlie various aspects of feeding. Two of these CPGs, the gastric mill (chewing) and pyloric (filtering) circuits, comprise most of the 26 neurons within the stomatogastric ganglion (STG). These circuits receive modulatory input from $\sim 20$ projection neurons, nearly all of which originate in the unpaired oesophageal ganglion (OG)

\footnotetext{
Received Jan. 24, 2007; revised April 20, 2007; accepted May 11, 2007.

This work was supported by National Institute of Neurological Disorders and Stroke Grant NS29436 (M.P.N.). We thank A. Cook and M. S. Kirby for contributing experiments to Figure 7.

Correspondence should be addressed to Dr. Michael P. Nusbaum, Department of Neuroscience, University of Pennsylvania School of Medicine, 215 Stemmler Hall, Philadelphia, PA 19104-6074. E-mail: nusbaum@mail.med.upenn.edu.

S. R. Saideman's present address: Department of Biological Sciences, Columbia University, 920 Fairchild Center, MC 2439, 1212 Amsterdam Avenue, New York, NY 10027.

DOI:10.1523/JNEUROSCI.0315-07.2007

Copyright $\odot 2007$ Society for Neuroscience $\quad$ 0270-6474/07/276664-11\$15.00/0
}

and paired commissural ganglia (CoGs) (Coleman et al., 1992; Nusbaum et al., 2001).

Distinct modulatory inputs elicit different versions of the pyloric rhythm (Marder and Thirumalai, 2002; Marder and Bucher, 2007). The core CPG for all of these rhythms is the electrically coupled pyloric pacemaker ensemble, which includes the anterior burster $(\mathrm{AB})$ neuron, a conditional endogenous oscillator, and the paired pyloric dilator (PD) neurons (Hooper and Marder, 1987; Ayali and Harris-Warrick, 1999). The core CPG for one version of the gastric mill rhythm in C. borealis has also been characterized. This rhythm is elicited by selective stimulation of modulatory commissural neuron 1 (MCN1), a single projection neuron in each CoG that innervates the STG (Coleman and Nusbaum, 1994). The core CPG for this rhythm includes the reciprocally inhibitory lateral gastric (LG) neuron and interneuron 1 (Int1) within the STG, plus MCN1 (Coleman et al., 1995; Bartos et al., 1999). A key mechanism underlying generation of this latter rhythm is that, regardless of its activity pattern, MCN1 releases its cotransmitters rhythmically within the STG because its STG terminals are rhythmically inhibited by the LG neuron (Coleman and Nusbaum, 1994; Coleman et al., 1995).

We showed previously that continuous superfusion of any one of several pyrokinin (PK) peptides, including C. borealis pyrokinin-I (CabPK-I) or CabPK-II, to the isolated STG elicits the gastric mill rhythm without activating MCN1 (Saideman et al., 2007). It is noteworthy that MCN1 does not contain CabPKs (Saideman et al., 2007). Consequently, the CabPK-elicited gastric mill rhythm uses a distinct core CPG from the one underlying the MCN1-elicited gastric mill rhythm. Here, we show that there are additional distinctions in the neurons contributing to the CPGs 

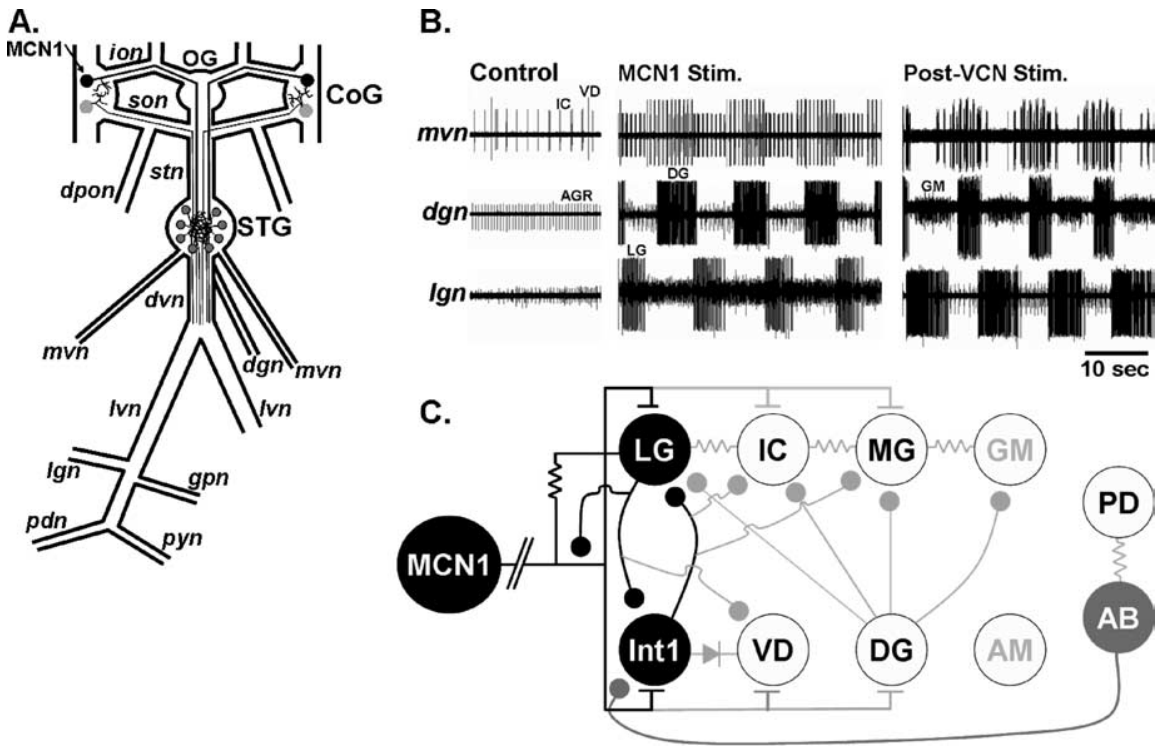

Figure 1. Schematic of the stomatogastric nervous system plus recordings of two different gastric mill rhythms. $A$, The STNS includes the paired $\mathrm{C} O G$ s, unpaired $O G$ and STG plus their connecting and peripheral nerves. Only some of the peripheral nerves are illustrated. The projection neuron MCN1 is labeled (arrow) in one CoG. dgn, Dorsal gastric nerve; dpon, dorsal posterior oesophageal nerve; $d v n$, dorsal ventricular nerve; gpn, gastro-pyloric nerve; ion, inferior oesophageal nerve; Ign, lateral gastric nerve; $m v n$, medial ventricular nerve; $p d n$, pyloric dilator nerve; pyn, pyloric nerve; son, superior oesophageal nerve; stn, stomatogastric nerve. $B$, Different gastric mill rhythms are elicited by activation of different pathways. Left, Before pathway stimulation, there was no gastric mill rhythm, but there was a pyloric rhythm $(m v n)$. Middle, Right, Extracellular recordings monitor the activity of five different gastric mill neurons during gastric mill rhythms elicited by selective stimulation of either MCN1 or the mechanosensory VCN neurons. The MCN1-elicited rhythm occurs during MCN1 stimulation, whereas the VCN-triggered rhythm occurs after VCN stimulation. Note that the IC neuron is active during protraction (LG burst) only during the MCN1-elicited rhythm, whereas the GM neurons are not active during this rhythm. C, Schematic illustration of the gastric mill circuit during MCN1 stimulation. Note that the CPG neurons are subdivided into the minimum set necessary for rhythm generation (black circles) and those whose activity regulates the basic rhythm (gray circle). The white circles represent follower motor neurons. Note that the GM and AM neurons (gray lettering) are either silent or weakly active in the MCN1-elicited rhythm. The pyloric pacemaker neurons AB and PD are included in this circuit because of the pivotal role of the inhibitory synapse from AB to Int1. All synapses shown occur in the STG. Filled circles, Synaptic inhibition; T-bars, synaptic excitation; resistors, nonrectifying electrical coupling; diode, rectifying electrical coupling. The line break in the MCN1 axon represents additional distance between the MCN1 soma (COG) and its gastric mill synapses in the STG.

underlying the CabPK- and MCN1-elicited gastric mill rhythms. Moreover, despite their distinct circuit configurations, the resulting gastric mill motor patterns are comparable in most respects. Therefore, neuromodulation can configure distinct CPGs to generate similar rhythmic motor patterns.

Parts of this work have been published previously in abstract form (Hertzberg et al., 2003; Hertzberg and Nusbaum, 2004, 2005).

\section{Materials and Methods}

Animals. Male Jonah crabs (C. borealis) were obtained from commercial suppliers (Commercial Lobster and Seafood, Boston, MA; Marine Biological Laboratory, Woods Hole, MA). Before experimentation, crabs were housed in commercial tanks containing recirculating, filtered, and aerated artificial seawater $\left(10^{\circ} \mathrm{C}\right)$. Before dissection, the crabs were coldanesthetized by packing them in ice for at least $30 \mathrm{~min}$. The foregut was then removed and maintained in chilled physiological saline while the STNS was dissected away from it.

Solutions. The STNS was maintained in physiological saline containing (in mM) $440 \mathrm{NaCl}, 26 \mathrm{MgCl}_{2}, 13 \mathrm{CaCl}_{2}, 11 \mathrm{KCl}, 10$ Trizma base, and 5 maleic acid, pH 7.4-7.6. CabPK (Biotechnology Center, University of Wisconsin, Madison, WI), Pevpyrokinin (PPK; Schoofs Laboratory, Leuven, Belgium; Protein Chemistry Laboratory, University of Pennsylvania, Philadelphia, PA) and Leucopyrokinin (LPK; Bachem, King of Prussia, PA; Protein Chemistry Laboratory, University of Pennsylvania,
Philadelphia, PA) were prepared as stock solutions $\left(10^{-3} \mathrm{M}\right)$ and then diluted to their working concentrations using physiological saline.

Electrophysiology. Electrophysiological experiments were performed using standard techniques for this system (Beenhakker and Nusbaum, 2004). The isolated STNS was pinned down in a Sylgard 184 (KR Anderson, Santa Clara, CA)-lined Petri dish (see Fig. 1A). All preparations were superfused continuously (7-12 $\mathrm{ml} / \mathrm{min}$ ) with C. borealis physiological saline $\left(10-12^{\circ} \mathrm{C}\right)$. Extracellular recordings were made by pressing a stainless-steel electrode into the Sylgard alongside each nerve of interest and isolating each area with Vaseline (Lab Safety Supply, Janesville, WI). The second electrode of each pair was pressed into the Sylgard in the main bath compartment. To facilitate intracellular recordings, the desheathed ganglia were viewed with light transmitted through a dark-field condenser (Nikon, Tokyo, Japan). Intracellular recordings of STG somata were made using microelectrodes (15-30 M $\Omega$ ) filled with $0.6 \mathrm{M} \mathrm{K}_{2} \mathrm{SO}_{4}$ plus $10 \mathrm{~mm} \mathrm{KCl}$. Intracellular current injection was performed using Axoclamp 2 amplifiers (Molecular Devices, Foster City, CA) in single-electrode discontinuous current-clamp (DCC) mode. Sample rates during DCC were $2-3 \mathrm{kHz}$.

Individual STNS neurons were identified by their axonal pathways, activity patterns, and interactions with other neurons (Beenhakker and Nusbaum, 2004). To study the influence of both CabPK and MCN1 on the gastric mill circuit under controlled conditions, in all experiments the CoGs were cut away by bisecting the inferior oesophageal (ion) and superior oesophageal (son) nerves. Eliminating the CoGs considerably reduces the background level of modulatory input to the STG by removing input from nearly all of the projection neurons that influence the STG (Beenhakker and Nusbaum, 2004). In this condition, there is a relatively slow and weak spontaneously active pyloric rhythm and no spontaneously active gastric mill rhythm.

Even with the CoGs removed, the MCN1 axon can be effectively and selectively stimulated extracellularly (ion stimulation) (Bartos and Nusbaum, 1997). Extracellular stimulation was effected using a Grass Telefactor S88 stimulator, via a stimulus isolation unit (SIU5, Astromed/ Grass Telefactor, West Warwick, RI). In all superfusion experiments, PK peptides were applied at a standard concentration $\left(10^{-6} \mathrm{M}\right)$. The actions of the four studied PK peptides (CabPK-I, CabPK-II, PPK, and LPK) were identical (Saideman et al., 2007), so the resulting data from all such applications were pooled for analysis.

Data acquisition and analysis. Data were collected directly onto a MT95000 or Everest chart recorder (Astromed), and were simultaneously digitized $(\sim 5 \mathrm{kHz})$ and collected onto a personal computer using data acquisition/analysis tools (Spike2; Cambridge Electronic Design, Cambridge, UK). Data analysis was facilitated with a custom-written program for Spike2 that determines the activity levels and phase relationships of neurons (freely available at http://cuniculina.biologie.uni-ulm.de/ wstein/spike2/The_Crab_Analyzer.s2s). Unless otherwise stated, each datum in a data set was derived by determining the average of 10 consecutive impulse bursts. Briefly, burst duration was defined as the duration between the onset of the first and last action potential in an impulse burst. The firing rate of a neuron was defined as the number of action potentials minus 1, divided by the burst duration. The cycle period of the pyloric rhythm was determined by measuring the duration between the onset of two successive PD neuron bursts. The gastric mill cycle period was de- 
termined by measuring the duration between the onset of two successive LG neuron bursts. The coefficient of variation (CV) was defined as the $\mathrm{SD}$ of the cycle period divided by the mean cycle period.

Phase analysis was performed on data collected from at least five preparations for each condition. Phase was defined as the latency to occurrence of an event relative to the start of a cycle, divided by the cycle period. Thus, for the gastric mill rhythm, the onset and offset of activity in each neuron after the onset of a LG neuron burst was measured as a fraction of the total cycle duration.

In some applications of $\mathrm{PK}$ peptides, the dorsal gastric (DG) neuron did not fire on every cycle of the gastric mill rhythm (defined by consecutive LG bursts). To determine the influence of such "uncoordinated" DG activity during an MCN1-elicited gastric mill rhythm, DG activity was manipulated with hyperpolarizing current injections. Specifically, for each experiment, 10 random numbers between two and four were generated and DG was alternately allowed to burst or hyperpolarized below burst threshold for the appropriate number of cycles. This manipulation resulted in a DG pattern comparable with that occurring during some PK applications in which DG was periodically off for two to four cycles. In both PK- and MCN1-elicited gastric mill rhythms with uncoordinated DG activity, the cycle period for 10 consecutive DG bursts plus the intervening cycles with no DG activity were analyzed instead of a total of 10 successive gastric mill cycles.

Figures were made from Spike2 files incorporated into Adobe (San Jose, CA) Photoshop, CorelDraw (Corel, Ottawa, Ontario, Canada), and Powerpoint graphics programs (Microsoft, Seattle, WA). Statistical analyses ( $t$ test, one way ANOVA, Mann-Whitney, Kruskal-Wallis one-way ANOVA on Ranks followed by Dunn's Method for pairwise comparisons) were performed with SigmaStat 3.0 and SigmaPlot 8.0 (SPSS, Chicago, IL). Data are expressed as mean \pm SD.

\section{Results}

MCN1 and PK peptides elicit similar gastric mill rhythms The biphasic gastric mill rhythm controls the rhythmic protraction and retraction movements of the paired lateral teeth and single medial tooth that mediate chewing in the middle (gastric mill) stomach compartment (Heinzel, 1988; Heinzel et al., 1993; Clemens et al., 1998a,b). In C. borealis, when this rhythm is cycling regularly, it has a cycle period that ranges from $\sim 5-20 \mathrm{~s}$ both in vivo and in the isolated STNS (Heinzel et al., 1993; Bartos et al., 1999; Beenhakker and Nusbaum, 2004). The gastric mill rhythm is composed of alternating impulse bursts of teeth protractor and retractor motor neurons, plus a single retractor phase Int1 (Fig. 1B,C) (Nusbaum and Beenhakker, 2002; Marder and Bucher, 2007). Several gastric mill neurons also exhibit impulse bursts that are time-locked to the pyloric rhythm, which is a faster rhythm (cycle period, $\sim 0.5-2 \mathrm{~s}$ ) whose motor neurons control the rhythmic constriction and dilation of the posterior stomach compartment (pylorus). The gastropyloric neurons include the gastric mill protractor neurons inferior cardiac (IC) and medial gastric (MG) and the retractor neurons Int1 and ventricular dilator (VD) (Fig. 1B) (Nusbaum and Beenhakker, 2002). All gastric mill neurons, except the protractor gastric mill (GM) neuron, occur as single copies in the $C$. borealis STG. There are four apparently equivalent GM neurons in this species.

Several versions of the gastric mill rhythm have been docu-
A.

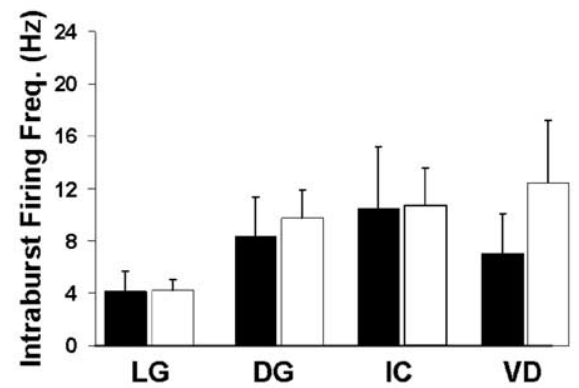

B.

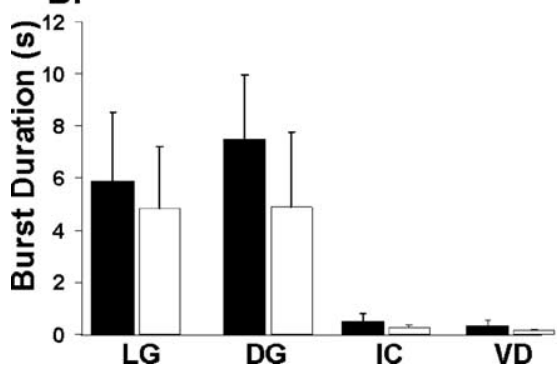

PK $\left(10^{-6} \mathrm{M}\right.$, w/o MCN1)

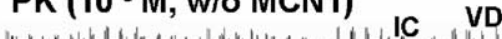

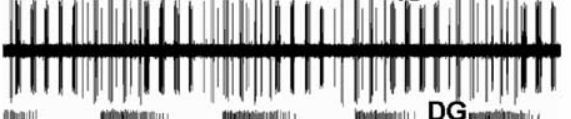

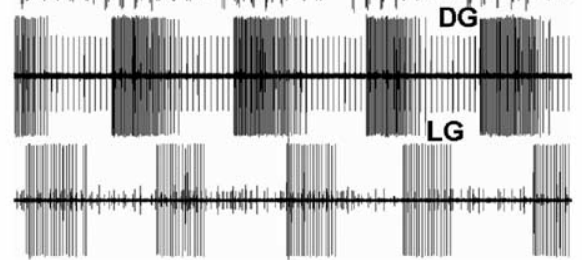

MCN1 Stim. (6 Hz, in Saline)

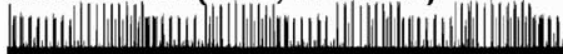

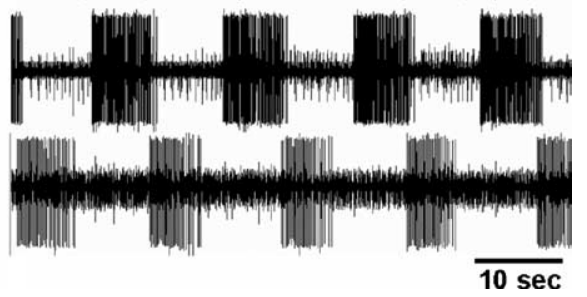

$\overline{10 \mathrm{sec}}$ rhythms were elicited in different preparations.

C.

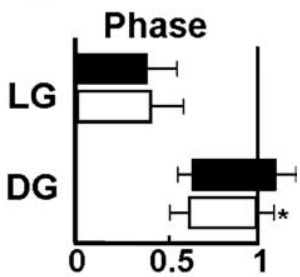

Norm. Cycle Per.

Figure 2. Comparable gastric mill rhythms are elicited by superfusion of PK peptide and selective stimulation of the projection neuron MCN1. Extracellular recordings of four gastric mill neurons (protractor $L G$ and IC neurons; retractor DG and VD neurons) are monitored during the PK- and MCN1-elicited gastric mill rhythms. Note the similarity in the timing of activity of these neurons

Figure 3. The PK- and MCN1-elicited gastric mill rhythms are quantitatively similar. Gastric mill rhythm parameters were analyzed and compared across preparations between the PK$\left(10^{-6} \mathrm{M}\right.$; filled bars) and MCN1-elicited ( $4-6 \mathrm{~Hz}$; open bars) rhythms $(n=4-11)$. $A-C$, These parameters included the $(\boldsymbol{A})$ intraburst firing frequency of four gastric mill neurons, $(\boldsymbol{B})$ burst duration of these same neurons, and $(\boldsymbol{C})$ phase relationship of the $L G$ and $D G$ neurons. The only difference occurred in the phase of the normalized gastric mill cycle at which the DG neuron burst terminated $\left(n=11 ;{ }^{*} p<0.01\right)$.

mented in $C$. borealis, including one driven by selective stimulation of the projection neuron MCN1 and ones triggered by extrinsic inputs, such as sensory pathways, that activate the rhythm via their excitation of projection neurons (Fig. $1 B$ ) (Coleman and 
Nusbaum, 1994; Beenhakker and Nusbaum, 2004; Blitz et al., 2004; Christie et al., 2004; Wood et al., 2004). All of these gastric mill rhythms share several features, including the presence of a two-phase rhythm composed of alternating protractor and retractor phases with a cycle period ranging from 5 to $20 \mathrm{~s}$. There is also rhythmic alternating bursting of the CPG neurons LG and Int1 in all of these rhythms and, in all cases, the retractor neurons VD and DG are coactive with Int1. Distinctions between these rhythms include the relative timing of the impulse bursts in the IC and MG neurons as well as the level of participation of the GM and anterior median (AM) neurons. For example, as shown in Figure $1 B$, IC neuron activity was distinct during the MCN1- and ventral cardiac neuron (VCN)-elicited gastric mill rhythms whereas GM neuron bursting occurred only during the VCNelicited rhythm. The MCN1-elicited rhythm is similarly distinct from the rhythms elicited by the gastropyloric receptor (GPR) and inferior ventricular nerve neurons (Blitz et al., 2004; Christie et al., 2004).

One of the best characterized gastric mill rhythms is the one elicited by tonic stimulation of MCN1 in preparations in which the CoGs are removed (Coleman and Nusbaum, 1994; Coleman et al., 1995; Blitz and Nusbaum, 1997; Bartos et al., 1999). MCN1 excites all of the gastric mill neurons (Fig. 1C). However, its influence on the GM and AM neurons is modest, particularly when they are inactive before MCN1 stimulation. Consequently, GM and AM are generally silent or only weakly active during the MCN1-elicited gastric mill rhythm. During this version of the gastric mill rhythm, the underlying CPG includes the gastric mill neurons LG and Int1 plus the STG terminals of MCN1 (Fig. 1C).

Many neuromodulators that are present in the STG terminals of projection neurons can activate and modify the pyloric rhythm when bath applied (Marder and Bucher, 2007). In some cases, bath application of the relevant neuromodulator mimics the pyloric circuit response to selective stimulation of the projection neuron that releases that substance. For example, the same pyloric rhythm is elicited by superfusion of the neuropeptide proctolin and intracellular stimulation of the modulatory proctolin neuron (Nusbaum and Marder, 1989a,b; Blitz et al., 1999). In contrast, no previously bath-applied modulators have activated the gastric mill rhythm in the isolated STG of C. borealis.

Recently, we showed that bath application of any one of several PK peptides $\left(10^{-6} \mathrm{M}\right)$ to the isolated STG routinely elicited rhythmic alternating bursting between the gastric mill CPG neurons LG (protraction) and Int1 (retraction) with a cycle period comparable with previously studied gastric mill rhythms (Saideman et al., 2007). The response to PK application also included appropriately timed bursting of the protractor-phase neurons MG and IC and the retractor phase VD neuron (Saideman et al., 2007). In many of those preparations, the retractor phase DG neuron also generated rhythmic bursting during PK application, but its activity was often not time-locked to that of the other gastric mill neurons. However, in some preparations, the DG bursts were time-locked with that of the other gastric mill neurons and a fully coordinated gastric mill rhythm was generated (Fig. 2A) (Saideman et al., 2007). The PK-elicited gastric mill rhythm appeared to be very similar to the rhythm elicited by selective stimulation of MCN1 in the isolated STG, and to be distinct from the other previously characterized versions of this rhythm (Figs. $1 B, 2)$.

The PK- $\left(10^{-6} \mathrm{M}\right)$ and MCN1-elicited gastric mill rhythms were particularly similar when MCN1 was stimulated tonically at a modest frequency $(4-6 \mathrm{~Hz})$ (Fig. 2). This similarity persisted
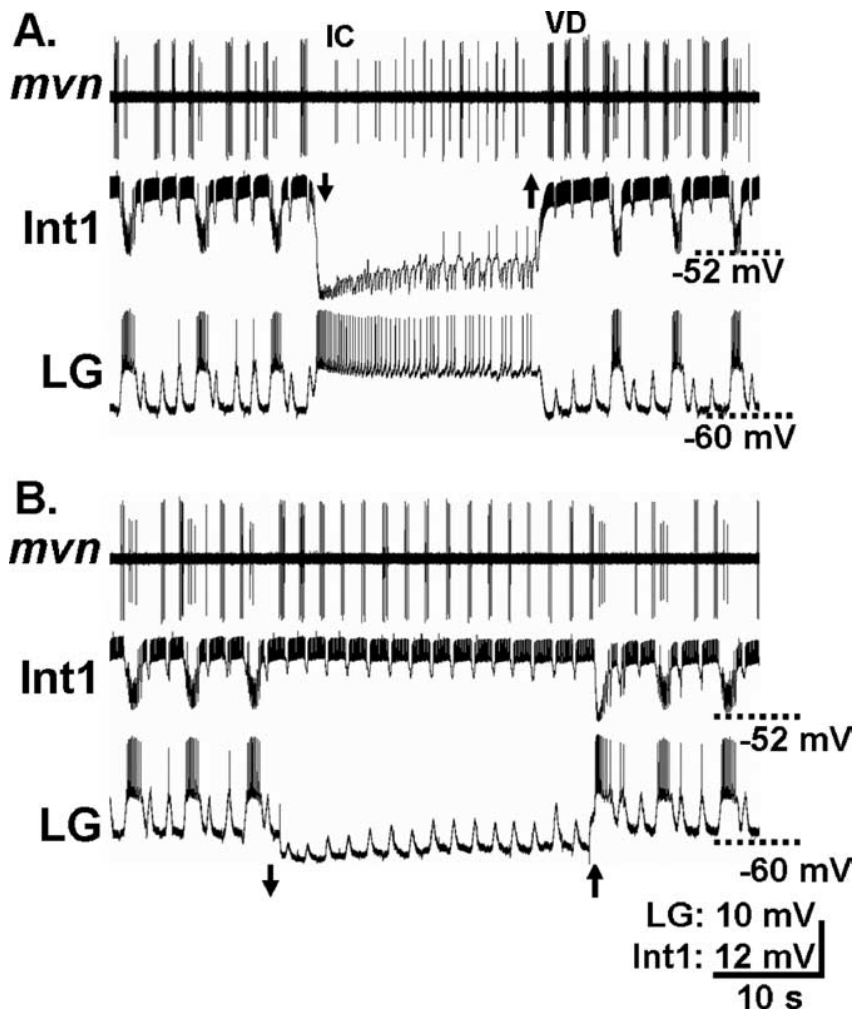

Figure 4. The reciprocally inhibitory $L G$ neuron and Int1 are both necessary for generation of the pyrokinin-elicited gastric mill rhythm. $\boldsymbol{A}$, During the PK-elicited $\left(10^{-6} \mathrm{M}\right)$ gastric mill rhythm, injection of constant amplitude hyperpolarizing current into Int1 (arrows, $-0.8 \mathrm{nA}$ ) terminated this rhythm. The rhythm returned after the end of this current injection. Note that, during Int1 hyperpolarization, activity in the $L G$ neuron switched from a rhythmic bursting pattern to tonic firing, whereas the IC and VD neurons resumed their purely pyloric-timed activity. $\boldsymbol{B}$, Suppression of $L G$ neuron activity (arrows, $-1.0 \mathrm{nA}$ ) during the ongoing PK-elicited gastric mill rhythm reversibly terminated this rhythm. While $L G$ neuron activity was suppressed, Int 1 and VD activity returned to be purely pyloric-timed whereas the IC neuron was silent. $A$ and $\boldsymbol{B}$ are from the same preparation.

when a representative set of gastric mill parameters were analyzed across preparations (Fig. 3). For example, there was no difference between the gastric mill cycle period of these two rhythms (PK, $16.1 \pm 3.9 \mathrm{~s} ; \mathrm{MCN} 1,12.4 \pm 4.3 \mathrm{~s} ; n=11 ; p>0.05)$. The same was true for the intraburst firing frequency and burst duration of the LG, DG, IC, and VD neurons (Fig. $3 A, B$ ). The phase of the normalized gastric mill rhythm at which the LG neuron burst terminated and the DG neuron burst initiated were also comparable during the MCN1- and PK-elicited rhythms (Fig. 3C). Among the 12 parameters analyzed, the only distinction between these rhythms pertained to the phase at which the DG neuron burst terminated. Specifically, the DG neuron burst terminated at the end of the gastric mill cycle during the MCN1 version of the rhythm and overlapped with the start of the LG neuron burst during the PK-elicited rhythm $(n=11 ; p<0.01)$ (Fig. $3 C)$. These rhythms were further similar in that the protractor GM neurons and the retractor AM neuron were either silent or weakly active during these rhythms (Coleman, 1995; Wood et al., 2000; Saideman et al., 2007). In contrast, the GM and AM neurons are consistently and strongly active in the other previously characterized gastric mill rhythms (Fig. 1B) (Beenhakker and Nusbaum, 2004; Blitz et al., 2004; Christie et al., 2004). 
The gastric mill half-center is necessary for the PK-elicited gastric mill rhythm Despite the similarity of the MCN1- and PK-elicited gastric mill rhythms, the underlying cellular and synaptic mechanisms by which they drove these rhythms were at least partly distinct. The distinction resulted from the facts that MCN1 was not active during the PK-elicited rhythm and MCN1 does not contain either of the CabPKs (Blitz et al., 1999; Saideman et al., 2007). Additionally, although MCN1 is stimulated tonically to elicit the gastric mill rhythm, its cotransmitter release is largely limited to each protractor phase of the gastric mill rhythm because of inhibition of its STG terminals by the LG neuron (Coleman and Nusbaum, 1994; Coleman et al., 1995). In contrast, the PK peptide is present constantly when it is superfused to activate the gastric mill rhythm (Saideman et al., 2007). It is noteworthy that despite some MCN1 actions being slow modulatory influences, such as its excitation of the LG and DG neurons, these influences decay within seconds when MCN1 is either synaptically inhibited or its stimulation is terminated (Coleman and Nusbaum, 1994; Coleman et al., 1995; Bartos and Nusbaum, 1997; Wood et al., 2000). This relatively fast decay is pivotal to LG burst termination during each cycle of this rhythm (Coleman et al., 1995). Additionally, this decay rate underlies the fact that the gastric mill rhythm consistently stops immediately when MCN1 stimulation is terminated $(n>50)$.

To determine whether there were any other differences in the mechanisms by which these two gastric mill rhythms were generated, we studied the influence of several gastric mill neurons on the PK-elicited rhythm. The core of the gastric mill CPG for the MCN1-elicited rhythm includes the reciprocally inhibitory neurons LG and Int 1 (Coleman et al., 1995; Bartos et al., 1999). We therefore determined whether these two neurons were also necessary for the generation of the PK-elicited gastric mill rhythm. To this end, we selectively suppressed the activity of either the LG neuron or Int 1 by intracellular hyperpolarizing current injection during an ongoing PK-elicited gastric mill rhythm. Suppressing either Int1 $(n=5)$ or LG neuron $(n=4)$ activity terminated the gastric mill rhythm (Fig. 4). In each case, the rhythm resumed when the current injection was terminated. Whenever Int1 activity was suppressed, the LG neuron changed from a gastric mill rhythm pattern of bursting to tonic activity (Fig. $4 A$ ). At these times, the IC and VD neurons returned to exhibiting exclusively a pylorictimed activity pattern (Fig. 4A). When the LG neuron activity was suppressed, Int 1 activity persisted as a pyloric-timed pattern, as did VD activity, whereas the IC neuron was silent (Fig. $4 B$ ). Int1 generally exhibits a pyloric-timed bursting pattern in the absence of the gastric mill rhythm (Fig. 5) (Bartos et al., 1999). It is also noteworthy that the trough of the subthreshold oscillations in the LG neuron was maintained at a steady membrane potential throughout each LG interburst, whereas the peak of these oscil- lations increased steadily $(n=11)$. Moreover, the membrane potential occurring at the trough of these LG oscillations $(-62.2 \pm 2.4 \mathrm{mV})$ was similar to the resting membrane potential of LG before the start of PK superfusion $(-63.4 \pm 1.2 \mathrm{mV} ; n=5$; $p>0.2$ ). In contrast, during MCN1 stimulation, the trough as well as the peak of the LG subthreshold oscillations commonly depolarize during each LG interburst, consistent with the ability of MCN1 to drive LG bursting even when the pyloric rhythm was suppressed (see below) (Bartos et al., 1999).

Whether the LG neuron or Int1 was hyperpolarized, the DG neuron continued to burst rhythmically during PK superfusion (Saideman, 2006). This rhythmic DG bursting was independent of the other STG neurons, and resulted from the unmasking of its intrinsic bursting ability by PK peptides (Saideman et al., 2007). Despite DG becoming an endogenous oscillator in the presence of PK, the PK-elicited gastric mill rhythm persisted when the DG neuron was either inactive or inactivated by hyperpolarizing current injection $(n=6)$ (Fig. 5A). The PK-elicited gastric mill rhythm also persisted during selective hyperpolarization of the protractor phase neurons IC $(n=2)$ and MG $(n=13)$ and the retractor phase neuron $\operatorname{VD}(n=6)$. The MCN1-elicited gastric mill rhythm also persisted through times when DG was inactivated by hyperpolarizing current injection $(n=6)$ (Fig. $5 B)$. This 


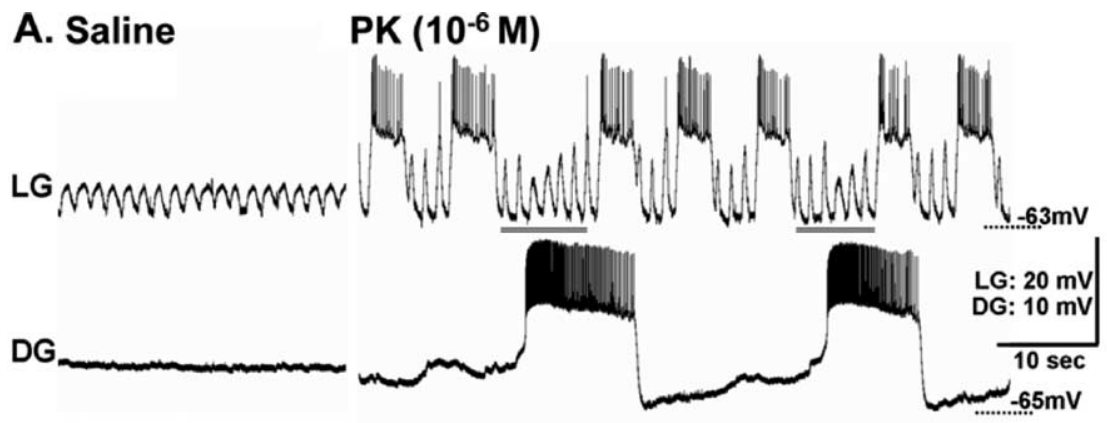

B. $\mathrm{PK}\left(10^{-6} \mathrm{M}\right)$

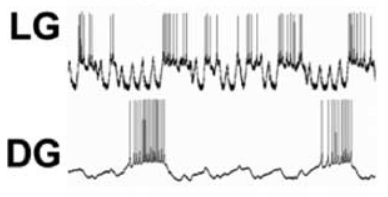

PK $\left(10^{-6} \mathrm{M}\right)$

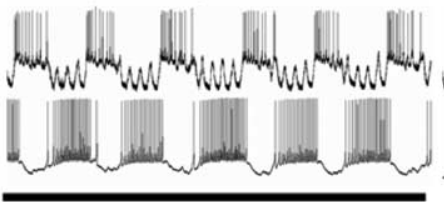

DG (+0.6 nA)

C. MCN1 Stimulation
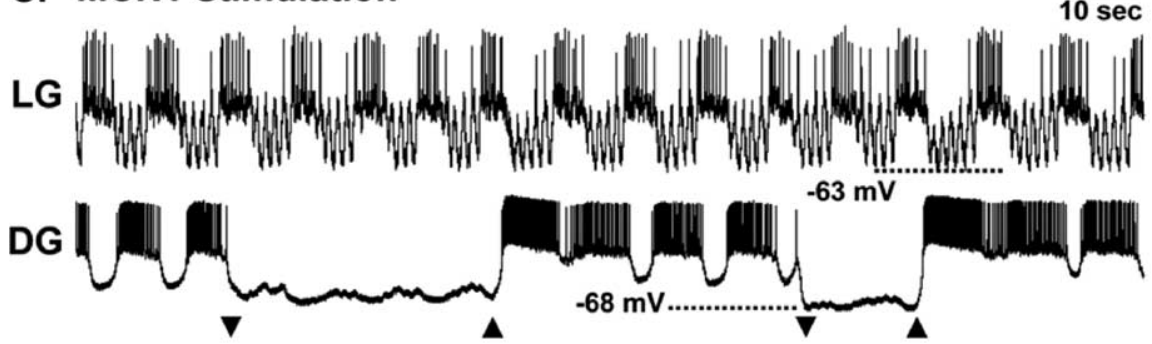

$-63 \mathrm{mV}$
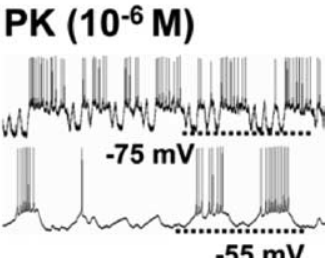

Figure 6. The $D G$ neuron regulates the duration of the retractor phase of the PK- but not the MCN1-elicited gastric mill rhythm. $A$, During PK superfusion, there was an ongoing gastric mill rhythm that included coordinated bursting of all activated gastric mill neurons except the $D G$ neuron. Instead, the DG neuron generated rhythmic bursts with a longer cycle period. Note that the duration of the LG interburst (retractor phase) was increased whenever a DG burst occurred (gray bars). At these times, there was a decreased amplitude of the pyloric-timed subthreshold depolarizations in the $L G$ neuron, particularly at the start of each DG burst. $B$, Regular rhythmic bursting in the DG neuron entrains the PK-elicited gastric mill rhythm. Left, During PK superfusion, there was an ongoing gastric mill rhythm, represented by $L G$ neuron bursting, during which all activated gastric mill neurons were coordinated except the DG, which burst independently at a slower cycle period. Note the increased retractor phase duration (LG interburst) during each DG burst. Middle, Intracellular injection of constant-amplitude depolarizing current into the DG neuron increased the regularity and frequency of its bursting. These regularly occurring DG bursts entrained the gastric mill rhythm (e.g., LG bursting). Right, Termination of the current injection in the DG neuron returned the system to its prestimulation condition. $C$, During the MCN1-elicited gastric mill rhythm, DG neuron activity was manipulated to mimic the irregular bursting that sometimes occurs during the PK-elicited rhythm. The DG neuron was alternately hyperpolarized below burst threshold (arrowheads) or allowed to burst for two to four cycles on a random basis.

latter rhythm also persisted during hyperpolarization of the IC, MG, or VD neuron (Coleman, 1995).

The DG neuron regulates the PK-elicited gastric mill rhythm During the PK-elicited gastric mill rhythms in which the DG neuron bursts were not time-locked with the other gastric mill neurons ("uncoordinated") (Saideman et al., 2007), the occurrence of each DG burst delayed the onset of the next anticipated LG neuron burst (Fig. 6A,B). This influence of the DG neuron on the LG cycle period was consistent across preparations $(n>20)$. Moreover, although the DG neuron did not burst during each gastric mill cycle in these preparations, LG neuron bursts rarely overlapped with the first half of a DG neuron burst, when the DG firing frequency was highest (Fig. 6A). Additionally, the peak amplitude of each subthreshold oscillation in LG was consistently
L: $30 \mathrm{mV}$

DG: $28 \mathrm{mV}$

$10 \mathrm{sec}$

DG: $20 \mathrm{mV}$

$10 \mathrm{sec}$

reduced during the first half of each DG burst ( $n=93$ of 100 cycles, 10 cycles each from 10 preparations), suggesting that DG effectively inhibited LG at these times (Fig. 6A) (Saideman, 2006).

We next determined whether the correlation noted in Figure $6 \mathrm{~A}$ indicated that the DG neuron did indeed regulate the timing of each LG burst, or was instead being activated in parallel by another neuron that was responsible for delaying $L G$ burst onset. To this end, when the DG bursts were irregular during PK $\left(10^{-6} \mathrm{M}\right)$ superfusion, we manipulated its activity by intracellular current injection and assessed the response of the LG neuron (Fig. 6B). Saideman et al. (2007) showed that the DG neuron is an endogenous oscillator in the presence of PK peptide, and it responds to continuous depolarizing current injection by increasing the frequency and regularity of its bursts. As expected, injecting such depolarizing current into the DG neuron during PK superfusion did indeed increase the frequency and the regularity of its bursts (Fig. 6B). This regularizing of the DG bursts in turn entrained the bursting activity of the LG neuron, as well as that of the other gastric mill neurons ( $n=4$ of 4 preparations) (Fig. $6 B$ ). Consequently, these depolarizations of the DG neuron produced fully coordinated gastric mill rhythms. When the current injection into the DG neuron was terminated, all gastric mill neurons returned to their preinjection activity patterns $(n=4)$ (Fig. 6B).

In contrast to the ability of DG to influence the PK-elicited gastric mill rhythm, this neuron had no impact on the MCN1elicited gastric mill rhythm (Coleman and Nusbaum, 1994). For example, periodic elimination of DG neuron activity during ongoing MCN1-elicited gastric mill rhythms, to mimic the uncoordinated DG activity during PK applications (see Materials and Methods), did not alter the regularity of those rhythms $(n=6)$ (Figs. $6 C, 7)$.

The mean gastric mill cycle period was equivalent when the DG neuron was silent and when it was bursting strictly in alternation with the LG neuron during PK superfusion $(n=10-15$; $p>0.05$ ) (Fig. 7A). The gastric mill cycle period occurring during times when the PK-elicited gastric mill rhythm included irregular DG neuron bursting was also comparable with the two aforementioned conditions $(n=20 ; p>0.05)$ (Fig. $7 A)$. Similarly, during MCN1 stimulations where we forced DG to burst irregularly by imposed hyperpolarizing current injections, there was no difference in the mean gastric mill cycle period relative to the MCN1elicited rhythms occurring when DG alternated with LG during every cycle or when DG was silent $(n=6 ; p>0.05)$ (Fig. $7 A)$.

We also performed a coefficient of variation analysis of the three gastric mill rhythm conditions during both PK superfusion and MCN1 stimulation to determine the impact of the DG neu- 

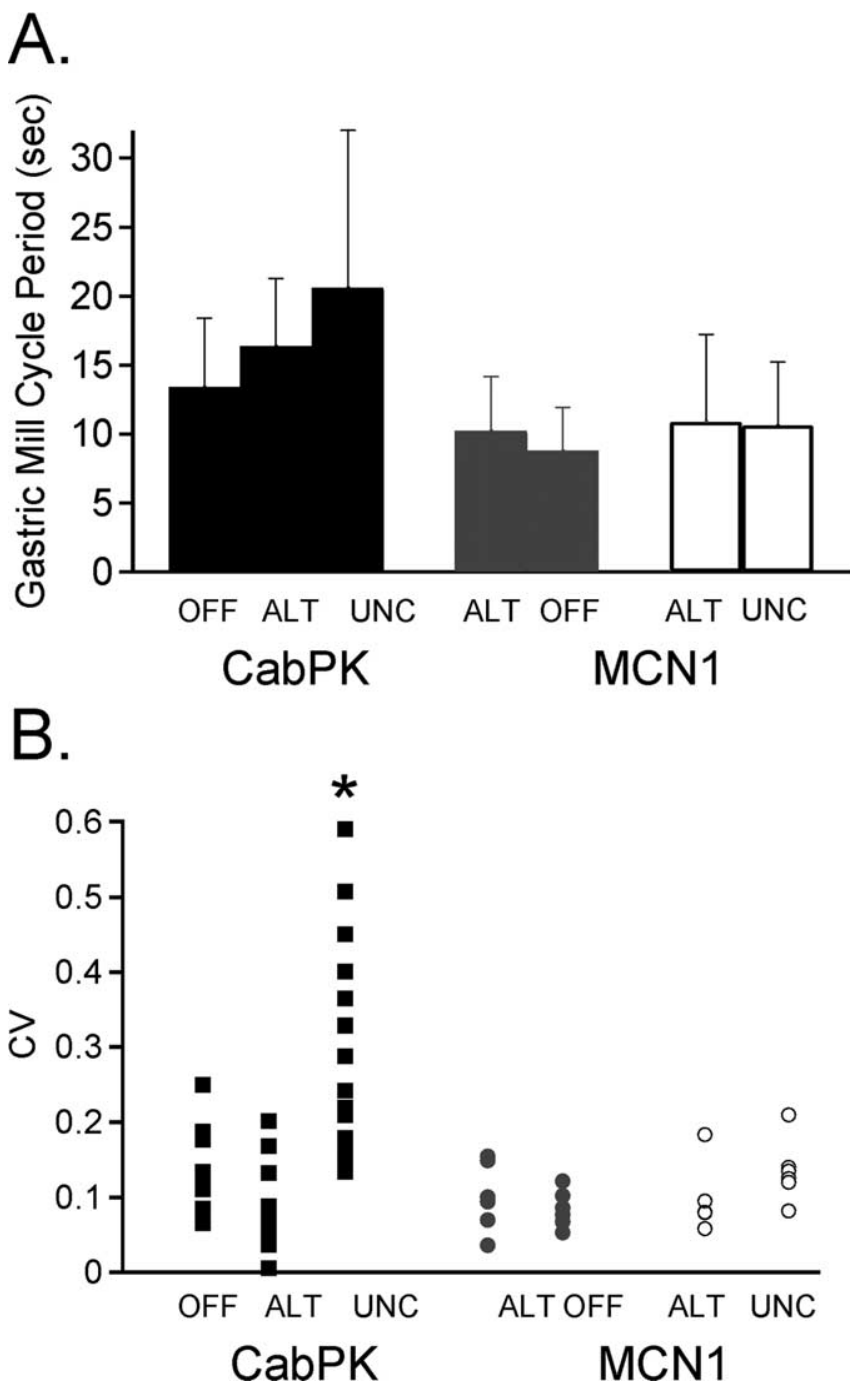

Figure 7. The pattern of DG neuron bursting determines the regularity of the PK- but not the MCN1-elicited gastric mill rhythm. $A$, The mean cycle period of the PK- and MCN1-elicited gastric mill rhythms was similar when the DG neuron was silent, alternating with $L G$ (alt), or uncoordinated with $\mathrm{LG}$ (unc) (PK conditions, $n=10-20 ; \mathrm{MCN} 1$ conditions, $n=6 ; p>0.05$ ). $B$, The CV of the PK- and MCN1-elicited gastric mill cycle periods is plotted as a function of the type of DG activity (PK, $n=10-20 ;$ MCN1, $n=6$ ). The PK-elicited rhythm exhibited more cycle-to-cycle variability when the $D G$ neuron bursts were not coordinated with the rhythm relative to times when the $D G$ neuron was either silent or burst in coordination with the other gastric mill neurons $\left({ }^{*} p<0.05\right)$. During MCN1-elicited gastric mill rhythms, DG activity was always coordinated with $L G$. Therefore, to mimic DG being silent or uncoordinated during subsets of PK-elicited rhythms, DG was either hyperpolarized consistently for 10 cycles (gray circles) or controlled to burst irregularly by alternately hyperpolarizing it below burst threshold and then allowing it to burst for two to four cycles (open circles) during MCN1-elicited rhythms. In the latter condition, data were analyzed across a total of 10 cycles with DG bursts, including the intervening DG silent cycles. "Alt" in each case refers to the control for the corresponding manipulation. There was no difference in CV across all conditions during MCN1-elicited rhythms $(p>0.05)$.

ron on the cycle to cycle variability evident in the PK-elicited rhythm (Fig. 6A,B) (Saideman et al., 2007). Our analysis indicated that, during PK superfusion, there was significantly more regularity within and between preparations for the gastric mill cycle period when the DG neuron was either silent or bursting regularly relative to times when the DG neuron was bursting irregularly $(n=10-20 ; p<0.05)$ (Fig. $7 B)$. The same coefficient of variation analysis during MCN1 stimulation showed that all three experimental conditions were comparable, indicating that
DG did not regulate the gastric mill cycle period during MCN1elicited gastric mill rhythms $(n=6 ; p>0.05)$ (Fig. $7 B)$.

\section{The pyloric rhythm is necessary for the PK-elicited gastric mill rhythm}

The pyloric rhythm regulates the cycle period of the MCN1elicited gastric mill rhythm by determining the onset time of each LG neuron burst (Bartos et al., 1999). This regulation of LG burst onset results from synaptic inhibition of Int 1 by the pyloric pacemaker neuron $\mathrm{AB}$. Each $\mathrm{AB}$-mediated inhibition of Int 1 causes a pyloric-timed depolarization (disinhibition) in LG (see Fig. $8 \mathrm{~A}$ ). During MCN1 stimulation, these pyloric-timed disinhibitions are increased in amplitude, because of MCN1 excitation of LG (Bartos et al., 1999). Under this condition, each LG burst is initiated during a pyloric-timed disinhibition, resulting in a regular coordination between the gastric mill and pyloric rhythms (Bartos et al., 1999). This coordination includes a latency locking between each LG burst onset and the $\mathrm{AB} / \mathrm{PD}$ neuron burst that indirectly triggered that LG burst. This latency locking persists over a range of pyloric cycle periods $(0.5-2.5 \mathrm{~s})$.

We assessed whether the pyloric rhythm regulated the PKelicited gastric mill rhythm in a manner comparable with its actions during MCN1 stimulation. As shown in Figure 8, the same pyloric rhythm events did occur during the PK-elicited gastric mill rhythm. For example, the amplitude of the pyloric-timed disinhibitions in the LG neuron were consistently increased by the presence of PK peptide $(n=33)$ (Figs. 5, 6A, $8 A$ ). The increased amplitude of these rhythmic disinhibitions in the LG presumably resulted from the excitatory action of the PK peptide onto the LG neuron (Saideman et al., 2007). Another parallel with the MCN1-elicited gastric mill rhythm is the fact that every LG neuron burst began during one of the pyloric-timed depolarizations ( $n=100$ of 100 cycles; 20 successive cycles from each of five preparations) (Fig. $8 \mathrm{~A}$ ). As in the MCN1-elicited gastric mill rhythm, the latency-locking between the onset of an LG burst and the onset of the immediately preceding $\mathrm{AB} / \mathrm{PD}$ neuron burst was consistent within each preparation, regardless of the pyloric cycle period ( $n=33$ ) (Fig. $8 B$ ). The pyloric cycle period was consistent within each preparation and, as in the comparable MCN1 experiments (Bartos et al., 1999), it ranged from 0.5 to $2.5 \mathrm{~s}$ across preparations (Fig. $8 \mathrm{~B}$ ). Additionally, in every preparation, the value of this latency relationship was smaller than the pyloric cycle period, indicating that each LG burst onset occurred within the pyloric cycle initiated by the measured pacemaker neuron burst (Fig. $8 A, B$ ).

During the MCN1-elicited gastric mill rhythm, the indirect $\mathrm{AB}$ regulation of $\mathrm{LG}$ burst onset is also the basis of the ability of the pyloric rhythm to regulate the gastric mill rhythm cycle period (Bartos et al., 1999). We therefore tested whether there was a comparable pyloric regulation of the PK-elicited gastric mill rhythm. To this end, during PK superfusion, we regulated the pyloric rhythm cycle period by injecting depolarizing or hyperpolarizing current into one or more pyloric pacemaker neurons. There was no complication of direct PK actions on the pyloric rhythm because this peptide does not alter the pyloric cycle period (Saideman et al., 2007). As shown in Figure 9A, the pyloric rhythm did indeed regulate the PK-elicited gastric mill rhythm $(n=12)$. Specifically, during relatively fast pyloric rhythms there was a relatively fast gastric mill rhythm, whereas slowing the pyloric rhythm consistently slowed the gastric mill rhythm. As the pyloric rhythm was slowed, its cycle-to-cycle variability increased (Fig. 9A,B). Correspondingly, the slower and more irregular py- 


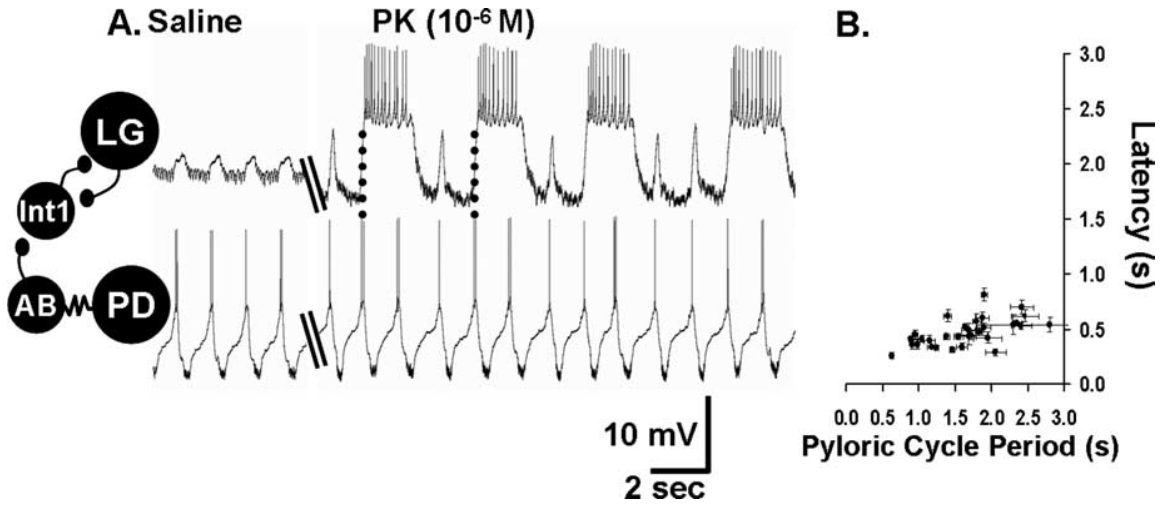

Figure 8. The pyrokinin-elicited gastric mill rhythm is coordinated with the pyloric rhythm. $A$, Left, During saline superfusion, there was no gastric mill rhythm (LG silent), but there was an ongoing pyloric rhythm (PD). The IPSPs recorded in the LG neuron resulted from Int1-mediated inhibition (circuit schematic), whereas the periodic elimination of these IPSPs and the associated depolarization (disinhibition) resulted from AB neuron-mediated inhibition of Int1 (circuit schematic) (Bartos et al., 1999). As indicated on the circuit schematic, the AB and PD neurons are electrically coupled and coactive. Right, During PK superfusion, the gastric mill rhythm was elicited while the pyloric rhythm continued. Note the increased frequency of Int1-mediated IPSPS, increased amplitude of the pyloric-timed disinhibitions, and the consistent onset of each LG neuron burst during one of these disinhibitions (dotted lines). Filled circles, Synaptic inhibition; resistor, electrical coupling. $\boldsymbol{B}, \mathrm{LG}$ neuron burst onset is latencylocked to the pyloric rhythm across preparations $(n=33)$. Scatter plot illustrates the mean latency from the onset of each PD neuron burst that triggers a $L G$ burst to the onset of that $L G$ burst, as a function of the pyloric cycle period. Each data point represents the mean $( \pm S D) P D-L G$ burst onset latency relationship from a single preparation, determined from 10 consecutive gastric mill cycles. The relatively small SD (vertical error bars) indicates the consistency of the latency relationship from cycle to cycle within each experiment.

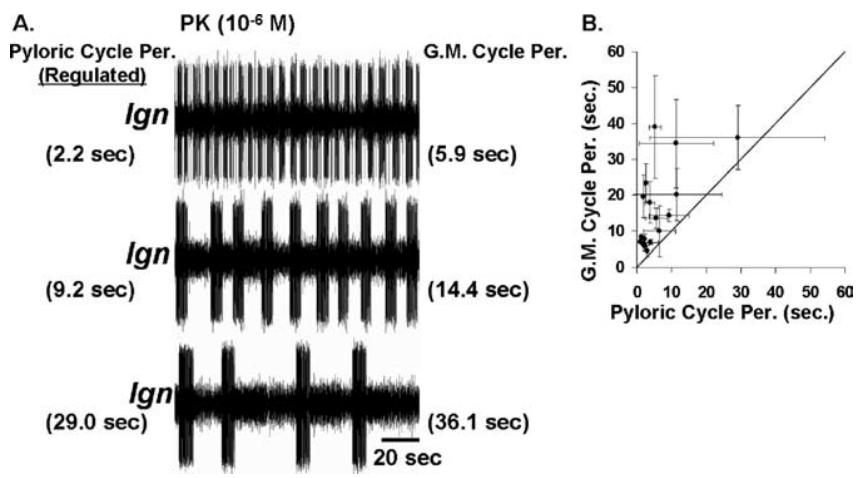

Figure 9. The pyloric rhythm regulates the PK-elicited gastric mill rhythm. $A$, Extracellular recordings of the $L G$ neuron during a PK-elicited gastric mill rhythm in which the pyloric cycle period was regulated by intracellular current injection in the PD neuron (data not shown). Increasing the pyloric cycle period caused an increased gastric mill cycle period, as indicated by the values for each rhythm alongside each recording. All three recordings are from the same preparation. $\boldsymbol{B}$, Across preparations, increasing the pyloric cycle period caused an increased and more variable PK-elicited gastric mill cycle period. There are three data points plotted, at three different regulated pyloric cycle periods, from each of five preparations. The three data points from within any single preparation were selected to represent a relatively fast, moderate and slow pyloric rhythm. As in $\boldsymbol{A}$, the pyloric cycle period was controlled by intracellular current injection in a PD neuron.

loric rhythms resulted in gastric mill rhythms with increased cycle-to-cycle variability (Fig. 9A,B).

We then tested whether the pyloric rhythm was necessary for generation of the PK-elicited gastric mill rhythm. We found that suppressing the pyloric rhythm consistently terminated the PKelicited gastric mill rhythm, even when the pyloric rhythm was suppressed for extended periods (3-20 $\min ; n=18$ ) (Fig. 10A). During these times, Intl became tonically active (data not shown), whereas the LG neuron was hyperpolarized by a constant barrage of IPSPs from Int1 (Fig. 10 A). In parallel, the DG neuron continued to burst rhythmically, but independently of all other
STG neurons (data not shown). The VD neuron also continued to burst irregularly in some preparations, although it fired tonically in others. In contrast, the IC and MG neurons exhibited no activity. When the hyperpolarizing current was removed from the pyloric pacemakers, enabling the resumption of the pyloric rhythm, the gastric mill rhythm resumed $(n=18)$ (Fig. 10A).

The dependence of the PK-elicited gastric mill rhythm on the pyloric rhythm was surprising in comparison to the MCN1elicited gastric mill rhythm. As reported previously (Bartos et al., 1999), the MCN1-elicited gastric mill rhythm consistently persisted in the absence of the pyloric rhythm, albeit with a longer cycle period (cycle period, with pyloric rhythm, $10.7 \pm 3.3 \mathrm{~s}$; without pyloric rhythm $28.8 \pm 11.0 \mathrm{~s} ; n=8)($ Fig. $10 \mathrm{~B})$. When the pyloric rhythm was suppressed during an ongoing MCN1-elicited gastric mill rhythm, the latency to the next LG burst was $27.2 \pm$ $19.3 \mathrm{~s}(n=8)$ (Fig. 10B). This latency is much shorter than the aforementioned 3-20 min during which there were no LG bursts when the pyloric rhythm was suppressed during PK application. Additionally, in the subset of preparations in which the pyloric rhythm was off during saline superfusion, PK superfusion did not activate this rhythm (Saideman et al., 2007), and it never elicited a gastric mill rhythm $(n=10)$.

\section{The PK-elicited gastric mill rhythm does not influence the pyloric rhythm}

During MCN1 stimulation, the gastric mill rhythm also regulates the pyloric rhythm (Bartos and Nusbaum, 1997). The pyloric rhythm consistently slows and weakens during each protractor (LG burst) phase of the gastric mill rhythm (Fig. 10B). This regulation results from LG inhibition of the MCN1 axon terminals in the STG, which reduces MCN1 excitation of the pyloric rhythm. In contrast, there was no gastric mill rhythm influence on the pyloric rhythm during PK superfusion (Fig. 11). The pyloric cycle period was the same during the protractor (LG burst) and retractor (LG interburst) phases of the PK-elicited gastric mill rhythm $(n=21)$ (Fig. $11 B)$.

\section{Discussion}

We have documented the ability of two different modulatory inputs to elicit neuronal activity patterns that were comparable in nearly every parameter analyzed. There were additional qualitative similarities between the MCN1- and PK-elicited gastric mill rhythms, including the presence of IC neuron activity during the LG burst and the absence of bursting in the GM and AM neurons. These features distinguished them from all other previously studied gastric mill rhythms (Beenhakker and Nusbaum, 2004; Blitz et al., 2004; Christie et al., 2004; Wood et al., 2004).

These two similar gastric mill rhythms might have resulted from convergent actions on the underlying CPG circuit. However, MCN1 stimulation and PK peptide application instead configured the same neuronal ensemble differently, so that each core CPG was composed of distinct sets of neurons with altered synaptic influences (Fig. 12). Although the ability of different networks to generate similar activity patterns is not well docu- 
mented, the ability of the same network to do so via different combinations of ionic and synaptic conductance strengths is supported by previous studies (Prinz et al., 2004; Schulz et al., 2006).

These conclusions extend our appreciation of the functional flexibility provided by neuromodulation. For example, it is well established that neuromodulation enables single networks to generate different neuronal activity patterns (Bacci et al., 2005; Marder et al., 2005; LeBeau et al., 2005; Lieske and Ramirez, 2006). Moreover, instead of changing the set of CPG neurons as occurred in our experiments, modulation of the pyloric network in the STG produces multiple outputs by changing the cellular and synaptic properties of a conserved set of CPG neurons (Hooper and Marder, 1987; Ayali and HarrisWarrick, 1999; Marder et al., 2005; Thirumalai et al., 2006). Although the identity of all network neurons has yet to be accomplished for most rhythmic motor circuits, previous studies of the mammalian respiratory CPG support the possibility that the core CPG neurons are distinct during different forms of respiration (Ramirez et al., 2004; Ramirez and Viemari, 2005).

All previously studied gastric mill rhythms in C. borealis are distinct, despite the fact that they all involve MCN1 activity (Coleman and Nusbaum, 1994; Beenhakker and Nusbaum, 2004; Blitz et al., 2004; Wood et al., 2004). These different rhythms result mainly from differences in the MCN1 activity pattern and/or firing rate, and the level of participation of a second projection neuron, commissural projection neuron 2. In all of these rhythms, the core CPG includes the reciprocally inhibitory STG neurons LG and Int1 plus the STG terminals of MCN1 (Coleman et al., 1995; Bartos et al., 1999; Wood et al., 2004; Beenhakker et al., 2005). MCN1 is considered to be a gastric mill CPG neuron as well as a rhythm activator because it must release its cotransmitter complement in a gastric mill rhythm-timed pattern to drive this rhythm (Coleman et al., 1995). This transmitter release pattern results from presynaptic inhibition of MCN1 by the LG neuron (Fig. 12A) (Coleman and Nusbaum, 1994).

The PK- and MCN1-elicited gastric mill rhythms were comparable, despite the fact that the PK peptide was continuously superfused while MCN1 cotransmitter release is rhythmic. Additionally, MCN1 does not contain CabPK (Saideman et al., 2007). The MCN1 cotransmitters include the peptides $C$. borealis tachykinin-related peptide Ia (CabTRP Ia) and proctolin, plus GABA (Blitz et al., 1999). Neither of the MCN1 peptide cotransmitters shares any amino-acid sequence similarity with the PK peptides. It remains to be determined if these distinct peptides converge downstream at the level of the affected second messenger system(s) and/or ion channels. The possibility of convergence in the LG neuron is supported by the fact that several neuropeptides, including CabTRP Ia and proctolin, have convergent actions on the same voltage-dependent current in C. borealis pyloric circuit neurons (Swensen and Marder, 2000, 2001). Moreover, the transmitter-mediated actions of MCN1 on LG result entirely from CabTRP Ia (Wood et al., 2000). The ionic current(s) influenced by the CabPKs remain to be determined. Divergent actions of CabPK and MCN1 are likely to occur in Int1, however, because the PKs have a slow, metabotropic-like excitatory action on Int 1, whereas MCN1 excites Int1 via an ionotropic GABAergic action (Coleman et al., 1995; Swensen et al., 2000; Saideman et al., 2007).

Despite the similarity of the PK- and MCN1-elicited gastric mill rhythms, there were clear distinctions in their core CPGs. As indicated above, the core CPG that enables the MCN1-elicited gastric mill rhythm includes LG, Int1, and MCN1 (Fig. 12A). The $\mathrm{AB}$ neuron is not necessary for generating the core rhythm during MCN1 stimulation, but it clearly regulates the speed of this rhythm (Fig. 12A). The PK-elicited gastric mill rhythm retains the need for rhythmic alternating activity between LG and Int1, but MCN1 does not participate in this rhythm and $\mathrm{AB}$ neuron activity is necessary for its occurrence (Fig. 12B). Furthermore, the DG neuron regulates the PK-elicited rhythm, although its activity is not necessary for the basic rhythm generation (Fig. $12 B$ ) (Saideman, 2006; present study). In contrast, the DG neuron is only a follower motor neuron during the MCN1-elicited rhythm (Fig. 12A) (Coleman and Nusbaum, 1994; present study). The switch in the role of the DG neuron from a follower neuron during MCN1 stimulation to an entrainer of the gastric mill rhythm during PK application appeared to result from strengthened DG inhibition of LG. The extent to which this strengthened synaptic action results from presynaptic and postsynaptic mechanisms awaits additional study.

The fact that $\mathrm{AB}$ neuron activity was necessary only for the PK-elicited gastric mill rhythm indicated a change in the cellular 


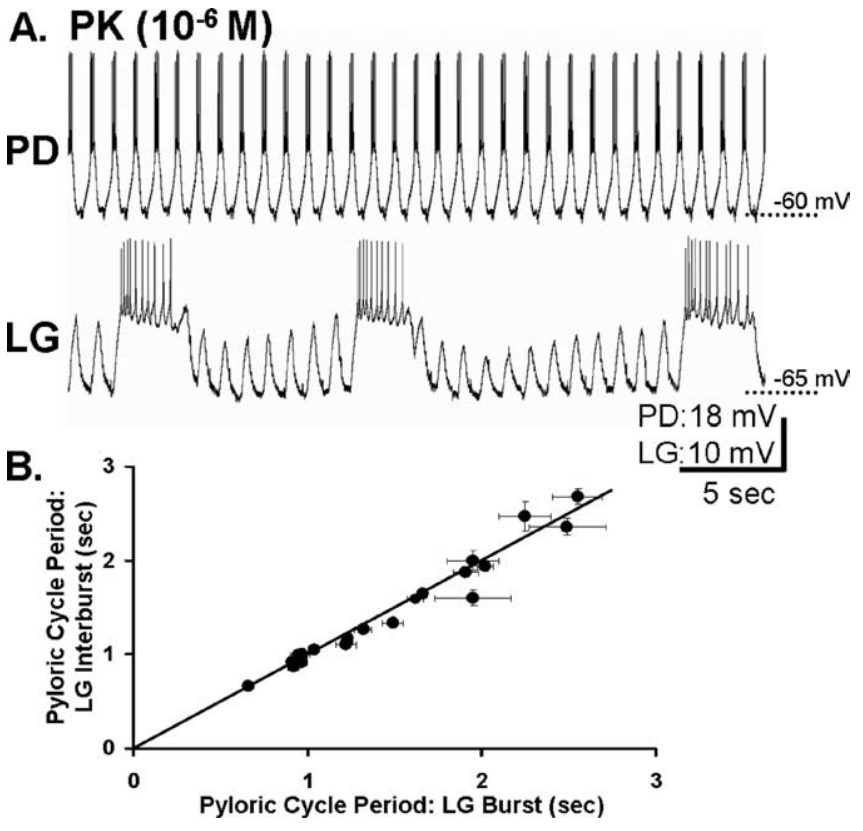

Figure 11. The PK-elicited gastric mill rhythm does not influence the pyloric rhythm. $\boldsymbol{A}$, During PK superfusion, the ongoing gastric mill rhythm (LG neuron) did not alter the cycle period of the ongoing pyloric rhythm, monitored here with an intracellular PD neuron recording. $\boldsymbol{B}$, Scatter plot of the mean pyloric cycle period during the gastric mill retractor phase (LG interburst) as a function of the pyloric cycle period during the gastric mill protractor phase (LG burst). Each data point is from a single preparation $(n=21)$ and represents the mean pyloric cycle period during 10 consecutive gastric mill retractor and protractor phases. Note that every data point lies on or near the unity line, indicating that the pyloric cycle period was consistently equivalent during both phases of the PK-elicited gastric mill rhythm.
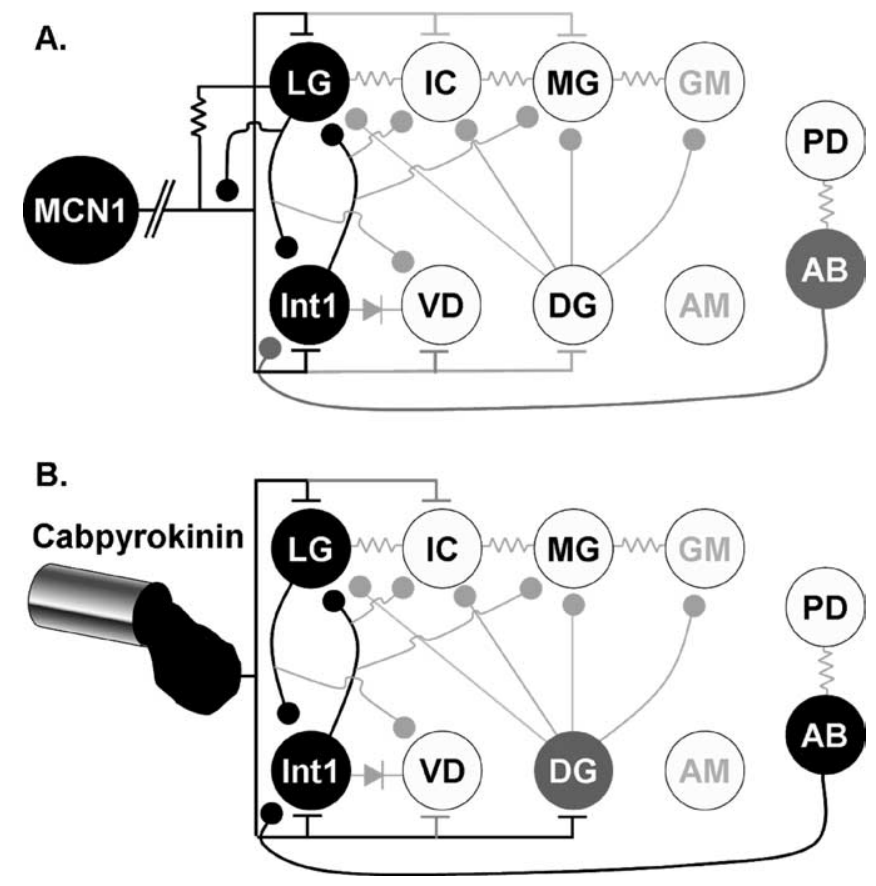

Figure 12. Schematic illustration of the distinct gastric mill CPGs during MCN1 stimulation and PK superfusion. Note the change in the roles of the DG and AB neurons in the two conditions. Black circles represent neurons necessary for rhythm generation, gray circles represent neurons that regulate the basic rhythm and white circles represent follower motor neurons. Gray lettering indicates neurons that do not contribute to this rhythm. Filled circles, Synaptic inhibition; T-bars, synaptic excitation; resistors, nonrectifying electrical coupling; diode, rectifying electrical coupling. mechanisms underlying LG burst generation during these two rhythms. During the PK-elicited rhythm, LG burst onset required postinhibitory rebound, triggered by $\mathrm{AB}$ inhibition of Int1. Thus, when the pyloric rhythm was suppressed the Intl inhibition of LG was constant, as well as stronger than PK excitation, which maintained LG at a hyperpolarized potential and prevented postinhibitory rebound bursts. In contrast, the continual buildup of MCN1 excitation enables LG to escape from Int1-mediated inhibition and fire an impulse burst when $A B$ activity is suppressed (Bartos et al., 1999; Beenhakker et al., 2005). However, during the MCN1 rhythm with an ongoing pyloric rhythm, each LG burst initiates during an episode of $A B$ inhibition of Int 1, suggesting that escape from inhibition and postinhibitory rebound both contribute to LG burst onset during this rhythm (Bartos et al., 1999).

The gastric mill CPG in C. borealis is considered to be a network-based oscillatory circuit which, by definition, includes no endogenously oscillatory neurons (Marder and Calabrese, 1996; Marder and Bucher, 2001). The rhythmic nature of such circuits depends on the interactions between the component CPG neurons. This condition underlies the core CPG for the MCN1-elicited gastric mill rhythm (Coleman et al., 1995). However, the PK-elicited gastric mill rhythm appears more appropriately defined as a hybrid CPG because, although it still relies on the reciprocal inhibition between LG and Int1, it also requires the intrinsic oscillatory activity of the $\mathrm{AB}$ neuron. The leech heartbeat $\mathrm{CPG}$ can also operate in either a network-based or intrinsic oscillatory mode (Cymbalyuk et al., 2002). However, in this latter system, there is a switch in the intrinsic properties of the same set of CPG neurons.

Thus far, the only functional distinction between these two gastric mill rhythms is that only the MCN1-elicited rhythm regulates the pyloric rhythm. Although the functional significance of changes in intercircuit regulation remains to be determined, changes in gastropyloric coordination do occur in the intact animal during different behavioral states, as well as in other systems (Clemens et al., 1998b; Bernasconi and Kohl, 1993; Saunders et al., 2004). Additional distinctions between the PK- and MCN1elicited gastric mill rhythms are likely to be identified, particularly those involving pathways that act via MCN1 and/or the DG neuron. For example, the GPR proprioceptor regulates the gastric mill rhythm by presynaptically inhibiting the STG terminals of MCN1 (Beenhakker et al., 2005). Whatever the influence of GPR on the PK-elicited rhythm, it cannot occur via MCN1. Additional study will also be necessary to determine the relationship between the actions of bath-applied PK peptide and its actions when neuronally released into the STG or as a circulating hormone (Saideman et al., 2007). These effects may well be comparable, however, because bath application can mimic the actions of both neuronally released modulators and circulating hormones in the STG (Nusbaum and Marder, 1989b; Katz and HarrisWarrick, 1990; Turrigiano and Selverston, 1990; Wood et al., 2000; Wood and Nusbaum, 2002).

The ability of neuromodulation to cause comparable activity patterns via distinct sets of CPG neurons and distinct cellular and synaptic properties has implications for drawing conclusions regarding potential mechanisms underlying motor pattern generation in less accessible motor systems. In these latter systems, the full complement of CPG neurons remains to be determined (Stein et al., 1997; Marder et al., 2005; Grillner, 2006). Thus, when comparable motor patterns are elicited in these systems by distinct pathways, the provisional conclusion that they are caused by activation of the same CPG neurons using the same underlying mechanisms will need to be tempered by the presence of alternative possibilities. 


\section{References}

Ayali A, Harris-Warrick RM (1999) Monoamine control of the pacemaker kernel and cycle frequency in the lobster pyloric network. J Neurosci 19:6712-6722.

Bacci A, Huguenard JR, Prince DA (2005) Modulation of neocortical interneurons: extrinsic influences and exercises in self-control. Trends Neurosci 28:602-610.

Bartos M, Nusbaum MP (1997) Intercircuit control of motor pattern modulation by presynaptic inhibition. J Neurosci 17:2247-2256.

Bartos M, Manor Y, Nadim F, Marder E, Nusbaum MP (1999) Coordination of fast and slow rhythmic neuronal circuits. J Neurosci 19:6650-6660.

Beenhakker MP, Nusbaum MP (2004) Mechanosensory activation of a motor circuit by coactivation of two projection neurons. J Neurosci 24:6741-6750.

Beenhakker MP, DeLong ND, Saideman SR, Nadim F, Nusbaum MP (2005) Proprioceptor regulation of motor circuit activity by presynaptic inhibition of a modulatory projection neuron. J Neurosci 25:8794-8806.

Bernasconi P, Kohl J (1993) Analysis of co-ordination between breathing and exercise rhythms in man. J Physiol (Lond) 471:693-706.

Blitz DM, Nusbaum MP (1997) Motor pattern selection via inhibition of parallel pathways. J Neurosci 17:4965-4975.

Blitz DM, Christie AE, Coleman MJ, Norris BJ, Marder E, Nusbaum MP (1999) Different proctolin neurons elicit distinct motor patterns from a multifunctional neuronal network. J Neurosci 19:5449-5463.

Blitz DM, Beenhakker MP, Nusbaum MP (2004) Different sensory systems share projection neurons but elicit distinct motor patterns. J Neurosci 24:11381-11390.

Christie AE, Stein W, Quinlan JE, Beenhakker MP, Marder E, Nusbaum MP (2004) Actions of histaminergic/peptidergic projection neuron rhythmic motor patterns in the stomatogastric nervous system of the crab Cancer borealis. J Comp Neurol 469:153-169.

Clemens S, Combes D, Meyrand P, Simmers J (1998a) Long-term expression of two interacting motor pattern-generating networks in the stomatogastric system of freely behaving lobster. J Neurophysiol 79:1396-1408.

Clemens S, Massabuau JC, Legeay A, Meyrand P, Simmers J (1998b) In vivo modulation of interacting central pattern generators in lobster stomatogastric ganglion: influence of feeding and partial pressure of oxygen. J Neurosci 18:2788-2799.

Coleman MJ (1995) Dynamic modulation of a rhythmically active neural network in the stomatogastric nervous system of the crab, Cancer borealis. PhD thesis, The University of Alabama at Birmingham.

Coleman MJ, Nusbaum MP (1994) Functional consequences of compartmentalization of synaptic input. J Neurosci 14:6544-6552.

Coleman MJ, Nusbaum MP, Cournil I, Claiborne BJ (1992) Distribution of modulatory inputs to the stomatogastric ganglion of the crab, Cancer borealis. J Comp Neurol 325:581-594.

Coleman MJ, Meyrand P, Nusbaum MP (1995) A switch between two modes of synaptic transmission mediated by presynaptic inhibition. Nature 378:502-505.

Cymbalyuk GS, Gaudry Q, Masino MA, Calabrese RL (2002) Bursting in leech heart interneurons: cell-autonomous and network-based mechanisms. J Neurosci 22:10580-10592.

Grillner S (2006) Biological pattern generation: the cellular and computational logic of networks in motion. Neuron 52:751-766.

Heinzel HG (1988) Gastric mill activity in the lobster. I. Spontaneous modes of chewing. J Neurophysiol 59:528-550.

Heinzel HG, Weimann JM, Marder E (1993) The behavioral repertoire of the gastric mill in the crab, Cancer pagurus: an in situ endoscopic and electrophysiological examination. J Neurosci 13:1793-1803.

Hertzberg SR, Nusbaum MP (2004) Pevpyrokinin elicits a MCN1-like gastric mill rhythm using different cellular mechanisms. Soc Neurosci Abstr 34:657.1.

Hertzberg SR, Nusbaum MP (2005) Different central pattern generators elicit similar gastric mill rhythms. Soc Neurosci Abstr 35:752.13.

Hertzberg SR, Huybrechts J, Schoofs L, Nusbaum MP (2003) Distinct mechanisms underlie similar activity patterns from the same circuit. Soc Neurosci Abstr 33:604.14.

Hooper SL, Marder E (1987) Modulation of the lobster pyloric rhythm by the peptide proctolin. J Neurosci 7:2097-2112.

Katz PS, Harris-Warrick RM (1990) Neuromodulation of the crab pyloric central pattern generator by serotonergic/cholinergic proprioceptive afferents. J Neurosci 10:1495-1512.

LeBeau FE, El Manira A, Griller S (2005) Tuning the network: modulation of neuronal microcircuits in the spinal cord and hippocampus. Trends Neurosci 28:552-561.

Lieske SP, Ramirez JM (2006) Pattern-specific synaptic mechanisms in a multifunctional network. II. Intrinsic modulation by metabotropic glutamate receptors. J Neurophysiol 95:1334-1344.

Marder E, Bucher D (2001) Central pattern generators and the control of rhythmic movements. Curr Biol 11:R986-R996.

Marder E, Bucher D (2007) Understanding circuit dynamics using the stomatogastric nervous system of lobsters and crabs. Annu Rev Physiol 69:291-316.

Marder E, Calabrese RL (1996) Principles of rhythmic motor pattern generation. Physiol Rev 76:687-717.

Marder E, Thirumalai V (2002) Cellular, synaptic and network effects of neuromodulation. Neural Netw 15:479-493.

Marder E, Bucher D, Schulz DJ, Taylor AL (2005) Invertebrate central pattern generation moves along. Curr Biol 15:R685-R699.

Nusbaum MP, Beenhakker MP (2002) A small-systems approach to motor pattern generation. Nature 417:343-350.

Nusbaum MP, Marder E (1989a) A modulatory proctolin-containing neuron (MPN). I. Identification and characterization. J Neurosci 9:1591-1599.

Nusbaum MP, Marder E (1989b) A modulatory proctolin-containing neuron (MPN). II. State-dependent modulation of rhythmic motor activity. J Neurosci 9:1600-1607.

Nusbaum MP, Blitz DM, Swensen AM, Wood D, Marder E (2001) The roles of co-transmission in neural network modulation. Trends Neurosci 24:146-154.

Prinz AA, Bucher D, Marder E (2004) Similar network activity from disparate circuit parameters. Nat Neurosci 7:1345-1352.

Ramirez JM, Viemari JC (2005) Determinants of inspiratory activity. Respir Physiol Neurobiol 147:145-157.

Ramirez JM, Tryba AK, Pena F (2004) Pacemaker neurons and neuronal networks: an integrative view. Curr Opin Neurobiol 14:665-674.

Saideman SR (2006) Circuit-specific modulation by neuroactive peptides. $\mathrm{PhD}$ thesis, University of Pennsylvania School of Medicine.

Saideman SR, Ma M, Kutz-Naber KK, Cook A, Torfs P, Schoofs L, Li L, Nusbaum MP (2007) Modulation of rhythmic motor activity by pyrokinin peptides. J Neurophysiol 97:579-595.

Saunders SW, Rath D, Hodges PW (2004) Postural and respiratory activation of the trunk muscles changes with mode and speed of locomotion. Gait Posture 3:280-290.

Schulz DJ, Goaillard JM, Marder E (2006) Variable channel expression in identified single and electrically coupled neurons in different animals. Nat Neurosci 9:356-362.

Stein PSG, Grillner S, Selverston AI, Stuart DG, eds (1997) Neurons, networks, and motor behavior. Cambridge, MA: MIT.

Swensen AM, Marder E (2000) Multiple peptides converge to activate the same voltage-dependent current in a central pattern-generating circuit. J Neurosci 20:6752-6759.

Swensen AM, Marder E (2001) Modulators with convergent cellular actions elicit distinct circuit outputs. J Neurosci 21:4050-4058.

Swensen AM, Golowasch J, Christie AE, Coleman MJ, Nusbaum MP, Marder E (2000) GABA and responses to GABA in the stomatogastric ganglion of the crab Cancer borealis. J Exp Biol 203:2075-2092.

Thirumalai V, Prinz AA, Johnson CD, Marder E (2006) Red pigment concentrating hormone strongly enhances the strength of the feedback to the pyloric rhythm oscillator but has little effect on pyloric rhythm period. J Neurophysiol 95:1762-1770.

Turrigiano GG, Selverston AI (1990) A cholecystokinin-like hormone activates a feeding-related neural circuit in lobster. Nature 344:866-868.

Wood DE, Nusbaum MP (2002) Extracellular peptidase activity tunes motor pattern modulation. J Neurosci 22:4185-4195.

Wood DE, Stein W, Nusbaum MP (2000) Projection neurons with shared cotransmitters elicit different motor patterns from the same neural circuit. J Neurosci 20:8943-8953.

Wood DE, Manor Y, Nadim F, Nusbaum MP (2004) Intercircuit control via rhythmic regulation of projection neuron activity. J Neurosci 24:7455-7463. 